\title{
Identifying the teaching content on substandard and falsified medical products in global pharmacy education as critical public health issue
}

\author{
Zuzana Kusynová 1,2 (D), Mart Kicken 1,2 (D), Hendrika A. van den Ham ${ }^{2}$ (D) Aukje K. Mantel-Teeuwisse ${ }^{2}$ (D) \\ ${ }^{1}$ International Pharmaceutical Federation (FIP), The Hague, The Netherlands \\ ${ }^{2}$ Utrecht Institute for Pharmaceutical Sciences (UIPS), Utrecht University, Utrecht, The Netherlands
}

\section{Keywords}

Pharmacy education

Pharmacy curriculum

Substandard and falsified (SF) medical products

\section{Correspondence}

Zuzana Kusynová

International Pharmaceutical Federation (FIP)

Andries Bickerweg 5

2517 JP The Hague

The Netherlands

zuzana@fip.org

\begin{abstract}
Aim: To gain insight into the education about substandard and falsified (SF) medical products. Method: A digital survey was sent to 173 different schools of pharmacy around the world. Results: The response rate was 32\% (55 responses, 37 countries). Most schools taught about SF medical products as a stand-alone course or as part of another course or module (67\%), whereas $33 \%$ did not teach about the subject. The main focus of teaching was on detection $(21 \%)$ and prevention (21\%) of SF medical products, while reporting was taught the least (12\%), indicating a knowledge gap in that area. A key barrier to introducing a new course that could close the gaps was insufficient time in pharmacy curriculum ( $n=33 ; 60 \%$ ), while availability of ready-to-adopt course materials was considered as a helpful enabler. Conclusion: These insights can improve the understanding on what is already being taught on SF medical products, where the gaps are and inform the curriculum needed globally.
\end{abstract}

\section{Introduction}

Substandard and falsified (SF) medical products are a substantial and understudied problem most prevalent in low- and middle-income countries (World Health Organization, 2017a; Ozawa et al., 2018;). According to the definition of the World Health Organization (WHO), substandard medical products fail to meet either national or international quality standards and/or specifications. Falsified medical products mispresent deliberately or fraudulently their identity, composition, or source (World Health Organization, 2017b). The importance of addressing the potential danger of SF medical products is confirmed by the WHO's mandate in tackling SF medical products (World Health Organization, n.d.) with prioritisation of eight high-level activities to counter SF medical products. These include improvement and focus on education and training. (World Health Organization, 2019). Furthermore, WHO developed a preventiondetection-response strategy (Director General Seventieth World Health Assembly, 2017). With regards to prevention of SF medical products, the desired outcome is improved product quality (e.g. strengthened oversight by regulators, improved manufacturing and supply chain integrity) and improved education and awareness. This requires the full involvement of the healthcare professionals working the closest with medical products and patients: the pharmacists (Ferrario et al., 2019; FIP (International Pharmaceutical Federation), 2021).

Pharmacists are crucial for not only ensuring pharmaceutical care and proper use and administration of medicines, but also are essential in assuring the integrity of the supply chain by taking up different roles from manufacturing to the safe procurement of medical products (Ferrario et al., 2019; FIP (International Pharmaceutical Federation), 2021). In addition, they play a key role in assuring the safety and quality of medical products, including prevention and detection of SF medical products, and in maintaining a reliable backward supply chain, e.g. product withdrawal and batch recall (FIP (International Pharmaceutical Federation), 2018). In many countries, 
pharmacists also have important roles in medical regulatory authorities (International Association of Medical Regulatory Authorities, n.d.), e.g. approval of (new) medicines, inspection of production facilities or fulfilling the role of a Qualified Person (QP) (FIP (International Pharmaceutical Federation, 2018).

Initial training and education of pharmacists vary by country, region and institution, but usually include a number of aspects related to quality in the production and safe use of medicines (Ferrario et al., 2019). Nevertheless, the United States Accreditation Council for Pharmacy Education pharmacy program of 2016 does not mention substandard or falsified medicines in their curriculum (Accreditation Council for Pharmacy Education, 2015). Moreover, a 2018 review of national pharmacy curricula in eight low- to middle-income countries (six Sub-Saharan African and two Asian countries) found only one country teaching about SF medical products (Ferrario A \& Wirtz VJ, 2018). Another study in the United Kingdom found that training on SF medical products was not included in the core pharmacy curriculum but was only provided as an elective global health module (Pyzik, 2018).

Globally, pharmacy educators need to adapt to new practice paradigms and stay ahead of the practice curve by providing students with the right knowledge and experience for the challenges they will be faced with as professionals (Kheir et al., 2008; Medina et al., 2013). Therefore, the aim of this study was to gain a global perspective of the current education of undergraduate pharmacy students (i.e. those finishing with a pharmacy diploma, typically ending with a Master or Doctor of pharmacy degree) on SF medical products and the approach universities take towards it. This insight will improve the understanding of what is already being taught on SF medical products and where the gaps are. In addition, this study tried to identify possible barriers and enablers for introducing new modules on this subject into the pharmacy curriculum.

\section{Methods}

\section{Setting and participants}

An online survey was sent to the director or head of 173 schools of pharmacy all over the world listed in the FIP Academic Institutional Members database. The authors have selected this international database as it collates active schools of pharmacy and pharmaceutical sciences participating in the global arena activities shaping the future of pharmacy education and practice. For demographic analysis, countries were indexed in low-, middle- and highincome countries using the World Bank list of economies (World Bank, 2020). Countries were additionally divided into different regions based on WHO 2020 region indication (World Health Organization, 2020). Data were collected in November and December 2020. The authors compared the respondents to the original group surveyed.

\section{Data collection}

The survey was created using LimeSurvey software and consisted of 27 mainly single and multiple-choice questions, divided into four sections. The first section of five questions covered general information about the participants (e.g. name, position, country) and their institution (undergraduate programme offered, number of academic years).

The second section of the survey concerned the courses offered about SF medical products. This section asked whether the school of pharmacy provides any education and, in case of a positive response, whether education is offered as a standalone course on SF medical products or if it is part of another module/course. The next nine questions concerned: if the subject SF medical products are being taught as a mandatory or elective course and/or through an optional certificate programme, what specific course(s) and/or lecture(s) are given about SF medical products, in which study year(s) are these courses/lectures given, what are the total hours that students spend on SF medical products (including all mandatory and elective hours), what prerequisite courses are required for students to take prior to the SF medical products course; as well as questions about course materials, classroom settings, evaluation methods of students' assessment and the academic background of the educators teaching the courses.

The third section of the survey concerned education content about SF medical products. Questions 16 to 23 concerned the specific topics covered on SF medical products in the pharmacy curriculum. The topics were selected based on the recently developed curriculum guide by the FIP in collaboration with the WHO, supported by the respective FIP competency framework (FIP (International Pharmaceutical Federation), 2021). The FIP competency framework maps to six teaching modules that deliver the competencies defined.

Next, there was a multiple-choice question about competencies linked to learning outcomes of SF medical products related courses in their pharmacy school (e.g. leadership, professionalism and social responsibility in responding to SF medical products, application of the scientific method in managing and investigating SF medical products) and lastly an open question concerning specification of materials used (e.g. key case studies, textbooks) for teaching about SF 
medicine topics corresponding to Modules A-F mentioned above.

The final survey section consisted of four questions with regard to potentially changing the current pharmacy curriculum of the participant's institution and the willingness to introduce a standalone course on SF medical products newly developed by the FIP in collaboration with the WHO. Two questions were multiple-choice questions about who approves the introduction of a new module into the current curriculum and what the possible barriers for implementation are. The last two questions used a quantitative five-point Likert scale concerning the likelihood of introducing a standalone module on SF medical products and the competencies of students with regard to detecting and action if exposed to SF medical products.

\section{Data analysis}

Quantitative data were analysed using Microsoft Excel 2013, and descriptive statistics were calculated. Open questions were analysed on keywords and key terms.

The number of total hours of students' education about SF medical products was quantified into a discrete number of total hours and divided into three groups indicating few ( $<5$ hours), moderate (5-15 hours) and high (>15 hours) number of hours. In cases where a range was given (e.g. 10-15 hours), the higher range number was taken. Answers in the form of " $x$ " number of credits or " $y$ " hours per calendar period were excluded from the results.

In terms of the content covered concerning SF medical products, the responses were averaged out to find out which module was being taught the most. Answers "None of the above" were excluded. Results for each module were presented in relation to other modules in order to improve the understanding of what is already being taught on SF medical products, where the gaps are and inform the curriculum needed globally.

The two five-point Likert scale questions were analysed, describing frequencies. Each point was converted into a linear distribution with an even interval of one to five: one = strongly disagree/not at all and five = strongly agree/very likely. The mean and standard deviation were calculated to examine whether the items contributed equally to the total scale score.

\section{Results \\ Demographics}

After three follow-up reminders, a total of 55 participants, representing faculties from 37 countries, completed the questionnaire (response rate of $32 \%$ ). Respondents came from middle- and high-income countries ( $n=29,(53 \%)$ and $n=26,(47 \%)$ respectively). The majority of participants came from the European Region (EUR, $n=16,29 \%$ ), followed by the Eastern Mediterranean Region (EMR, $n=11,20 \%$ ), and the Western Pacific Region (WPR, $n=11,20 \%$ ) (Table I). This corresponds to the original group surveyed from the FIP AIM database $(n=173)$, with majority of schools in middle- $(n=72,42 \%)$ and high-income ( $n=100,58 \%)$ countries; and regionally spread representation: the Region of the Americas (AMR, $n=52,30 \%$ ); the European Region (EUR, $n=35,20 \%)$, the Western Pacific Region (WPR, $n=29,17 \%$ ), the Eastern Mediterranean Region (EMR, $n=26,15 \%)$, the South-East Asia Region (SEAR, $n=18,10 \%$ ) and the African Region (AFR, $n=13$, $8 \%)$.

Table I: WHO regions participants

\begin{tabular}{lll}
\hline WHO region & $\mathbf{n}$ & $\mathbf{( \% )}$ \\
\hline AFR & 5 & $9 \%$ \\
EMR & 11 & $20 \%$ \\
EUR & 16 & $29 \%$ \\
AMR & 7 & $13 \%$ \\
SEAR & 5 & $9 \%$ \\
WPR & 11 & $20 \%$ \\
\hline Total & $\mathbf{5 5}$ & $\mathbf{1 0 0 \%}$ \\
\hline
\end{tabular}

Abbreviations: AFR = African Region; EMR = Eastern Mediterranean Region; EUR = European Region; AMR = Region of the Americas; $S E A R=$ South-East Asia Region; WPR = Western Pacific Region

Most institutions provided undergraduate programmes with a bachelor in pharmacy (B.Pharm, $n=38,69 \%$ ), followed by a master of pharmacy (M.Pharm, $n=28$, $51 \%$ ), doctor(ate) of pharmacy (PharmD, $n=18,33 \%$ ) and/or other degree ( $n=5,9 \%$, e.g. Bachelor or Doctoral Pharmaceutical Sciences). Furthermore, most undergraduate pharmacy programmes offered lasted four $(n=21,38 \%)$ or five years $(n=22,40 \%)$, whereas $11 \%(n=6)$ of programmes had a duration of six years and $7 \%(n=4)$ more than six years.

\section{Course information}

Of all universities, 33\% $(n=18)$ did not teach about SF medical products specifically. A further 37 (67\%) schools taught about SF medical products as part of another course or module $(n=35)$ or as a standalone course $(n=2)$. Most of them taught about SF medical 
products as a mandatory course $(n=32,86 \%)$ and some as an elective course $(n=6,16 \%$, three institutions provide both elective as mandatory courses). Two respondents did not know the course status for their university (5\%). None of the schools offered an optional certificate programme on SF medical products. Appendix A shows the results of the analysis of open questions based on key terms used, i.e. lists the specific course(s) and/or lecture(s) given about SF medical products provided by participants.

Moreover, a majority of institutions tended to teach SF medical products in the middle-later years (Figure 1).

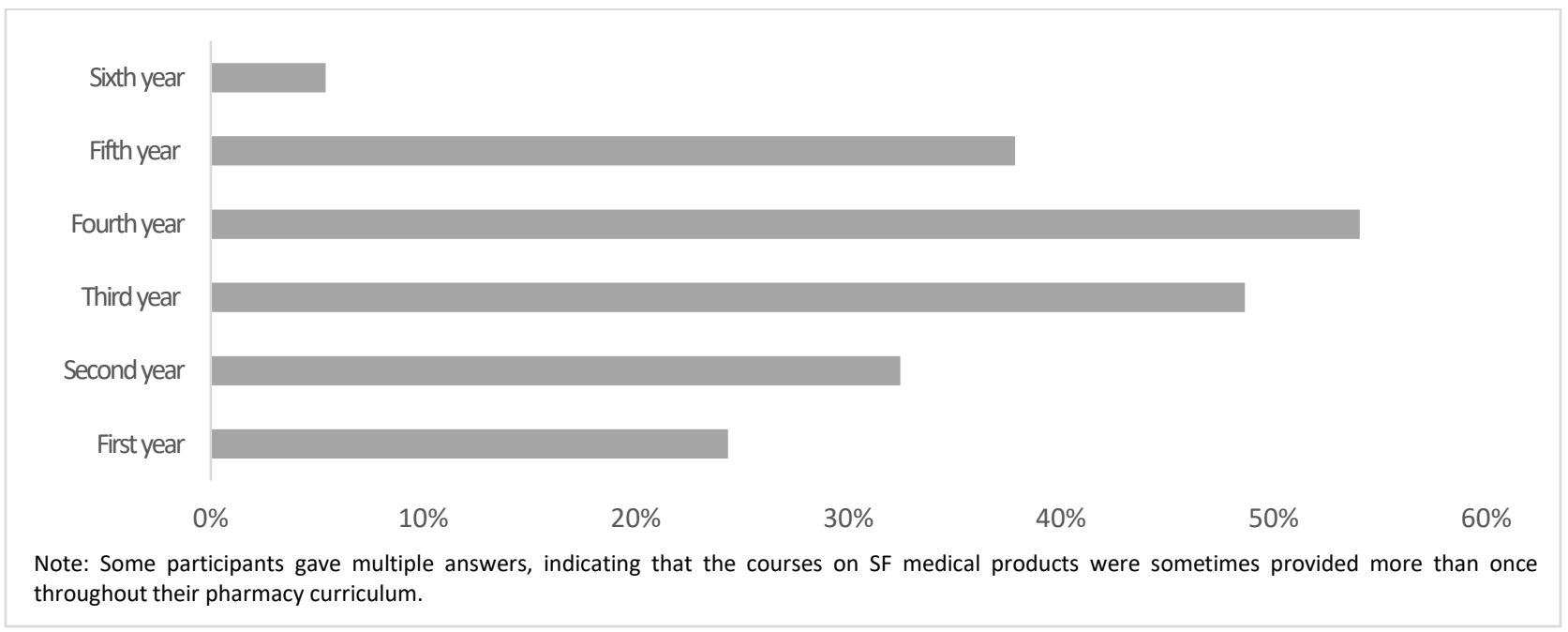

Figure 1: Overview of which study year(s) courses/lectures about SF medical products are provided (multiple answers possible, $\%, n=37$ )

As for the total number of hours students spent on SF medical product education, 33 institutions replied. 14 (42\%) universities provided less than five hours of education, eight (24\%) between 5-15 hours and 11 (33\%) more than 15 hours. Regarding prerequisites required for students prior to taking the course on SF medical products, the focus was on analytical chemistry (qualitative and quantitative analysis, $n=26,70 \%$ ) followed by pharmaceutical chemistry ( $n=22,60 \%)$ (Figure 2).

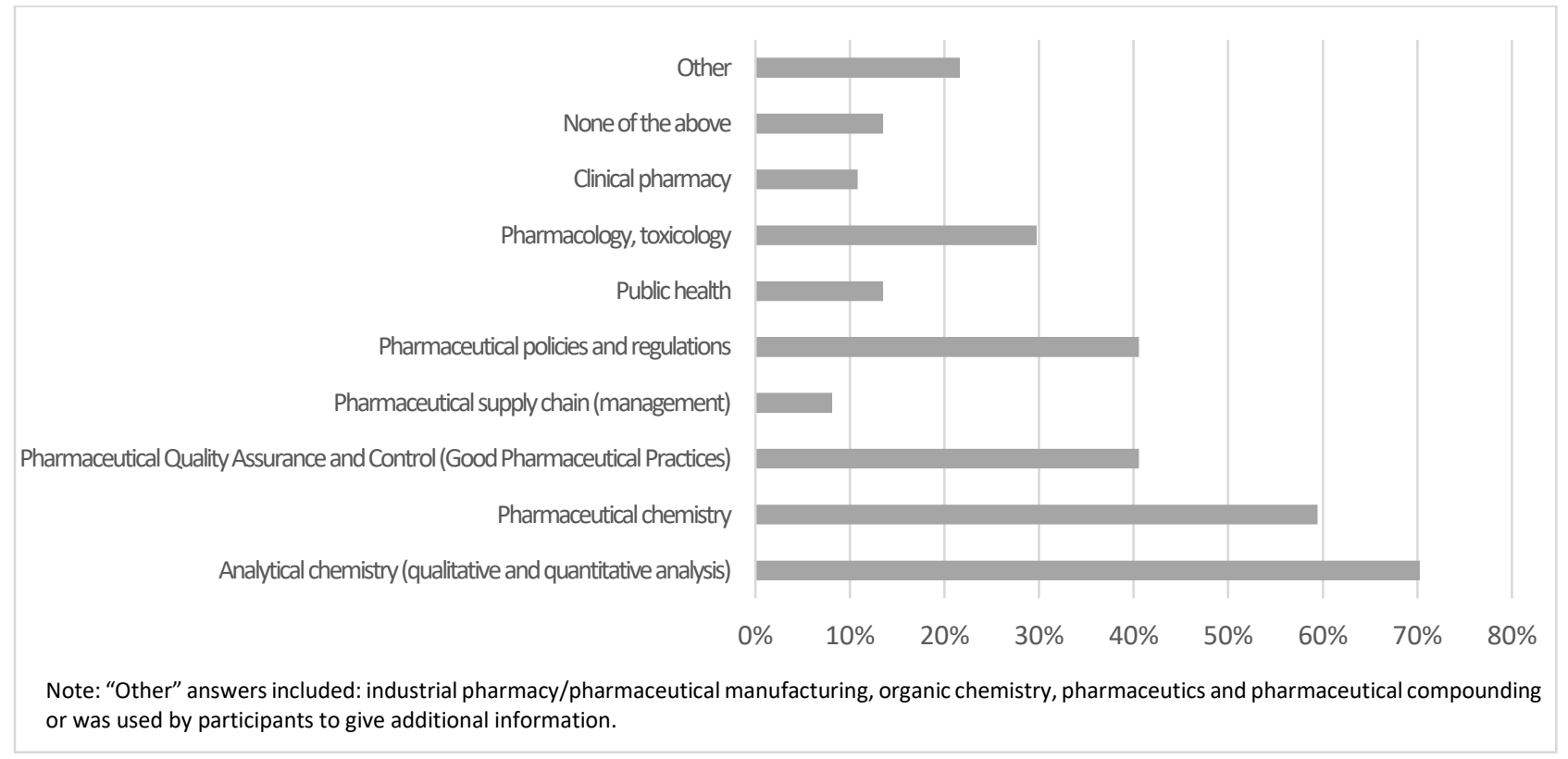

Figure 2: Courses required for students to take prior to taking the courses on SF medical products (multiple answers possible, $\%, n=37$ ) 
With regard to course methods used for education about SF medical products, traditional methods (e.g. lectures, seminars, tutorials) were the most prevalent ( $n=34,92 \%)$ followed by $46 \%(n=17)$ of institutions using non-traditional methods like problem-, team- and case-based learning. A further three schools indicated other means: field visits $(n=1,3 \%)$ and laboratory practices $(n=2 ; 5 \%)$.

Almost all universities taught in a classroom setting ( $n=36,97 \%)$. In addition, 11 universities taught in a practice setting as well (e.g. hospital, 30\%) and 16 by virtual means (before COVID-19, $n=16,43 \%$ ), whereas four universities indicated other means: laboratory practicals $(n=3,8 \%)$ and, placement in industry and regulatory bodies $(n=1,3 \%)$.

Evaluations used to assess students' education about SF medical products were mostly done as a written exam $(n=36,97 \%)$ or laboratory examination $(n=17$, $46 \%)$. Other forms of evaluations were oral exam $(n=9,24 \%)$, essay writing $(n=7,19 \%)$, testimonials from practice $(n=5,14 \%)$, role play $(n=4,11 \%)$ and portfolio $(n=3,8 \%)$.

Moreover, the educational background of educators teaching about SF medical products were mainly university-employed pharmacists with regular or minimal patient contact (respectively $n=22,59 \%$; $n=21,57 \%)$, followed by practising pharmacists ( $n=14,38 \%)$, non-pharmacists $(n=6,16 \%)$ and nonpharmacy medically qualified staff $(n=5,14 \%)$. Furthermore, three universities (8\%) indicated other: background in industrial pharmacy $(n=1,3 \%)$, chemistry $(n=1,3 \%)$ and college faculty $(n=1,3 \%)$.

Materials used (e.g. key case studies, textbooks or resources) to teach about the SF medical products are listed in Appendix B.

\section{Course content}

With regard to the total of SF medical education, each of the total of six modules were (partly) covered by the responding programmes combined. Table II shows the contribution of each module to this total. Module C (prevention) and D (detection) were relatively to other modules being taught the most (both $21 \%$ ), followed by Module A (introduction to SF medical products, $17 \%)$.
Table II. Modules A-F covered

\begin{tabular}{lc}
\hline Modules & Percentage \\
\hline Module A & $17 \%$ \\
Module B & $16 \%$ \\
Module C & $21 \%$ \\
Module D & $21 \%$ \\
Module E & $12 \%$ \\
Module F & $13 \%$ \\
\hline
\end{tabular}

Module $\mathrm{A}=$ general introduction to SF medical products; Module $\mathrm{B}=$ identification of medical products at risk; Module $C=$ prevention of SF medical products (from entering the supply chain); Module $D=$ detection strategies for SF medical products; Module E = reporting SF medical products; Module $\mathrm{F}=$ intervention after coming in contact with SF medical products. Answers "None of the above" were excluded.

Each module contained questions about the subtopics taught concerning SF medical products. Under Module A (introduction to SF medical products), most schools taught about legislation and regulation protecting the integrity of the supply chain (e.g. quality assurance, surveillance), while $2 \%(n=5)$ did not teach about this subtopic. For Module $B$ (identification), most schools taught about the characteristics of medical products at risk, risks of online and illegal markets and the importance of good pharmaceutical care, while $3 \%(n=6)$ did not teach about identification of SF medical products. For Module C (prevention), most schools taught about the principles of pharmaceutical Quality Assurance (e.g. good practice guidelines), while $4 \%(n=7)$ did not teach about this subtopic. For Module D (detection), Quality Control (e.g. pharmacopeia, compliance with regulatory requirements) was taught the most, while $3 \%(n=5)$ did not teach about this subtopic. For Module E (reporting), most schools taught about reporting incidences of SF medical products through national authorities, while $14 \%(n=15)$ did not teach about this subtopic. For Module $\mathrm{F}$ (intervention), most schools taught about recognising the effects of exposure to SF medical products (e.g. pharmacology, toxicology of (SF) medical products), while $13 \%(n=18)$ did not teach about this subtopic (Table III). 


\section{Table III: Number (and percentage) of schools teaching content of Modules A-F}

\begin{tabular}{ll} 
Number (and percentage) of schools teaching content of Modules A-F \\
\hline $\begin{array}{ll}\text { Module A: introduction to SF } & \text { Legislation and regulation protecting the integrity of the supply chain (e.g. quality assurance, surveillance) } \\
\text { medical products } & (n=38 ; 15 \%)\end{array}$
\end{tabular}

medical products

Proportion of all modules ${ }^{\dagger}: 17 \%$ $(n=38 ; 15 \%)$

Regulation of medical products (e.g. pharmacovigilance and drug inspection) ( $n=36,15 \%)$

Internationally accepted terminology (e.g. substandard and falsified medical products vs counterfeit) and definitions ( $n=33,13 \%)$

Health, social and economic consequences $(n=32,13 \%)$

Pharmaceutical policy $(n=30,12 \%)$

SF medical products contributing to antimicrobial resistance (AMR) ( $n=21,8 \%)$

The history of incidences of SF medical products ( $n=20,8 \%)$

Advocacy at national, regional, and international levels ( $n=17,7 \%)$

Key stakeholders in the fight and campaign against SF medical products and their roles and activities ( $n=16$, $6 \%)$

Module B: identification

Proportion of all modules ${ }^{\dagger}: 16 \%$

Module C: prevention

Proportion of all modules ${ }^{\dagger}: 21 \%$

Module D: detection

Proportion of all modules ${ }^{\dagger}: 21 \%$

Module E: reporting

Proportion of all modules ${ }^{\dagger}: 12 \%$

Module F: intervention

Proportion of all modules ${ }^{\dagger}: 13 \%$

None of the above $(n=5,2 \%)$

Characteristics of medical products that are most at risk of being substandard and/or falsified (e.g. expensive/lifestyle medicines) ( $n=31,17 \%)$

Risks of online market \& illegal online pharmacies $(n=31,17 \%)$

The importance of good pharmaceutical care $(n=31,17 \%)$

Contributing factors (e.g. medicines shortages, weak legislation, ineffective data sharing) $(n=25,14 \%)$

Resources to find factual, reliable information on SF medical products ( $n=21,12 \%$ )

Extent of incidences and scale of the problem (e.g. through pharmacoepidemiology and investigating medicine use) ( $n=19,11 \%)$

Drivers (e.g. socio-economic drivers) $(n=14,8 \%)$

None of the above $(n=6,3 \%)$

Principles of pharmaceutical Quality Assurance (e.g. Good practice (GxP) guidelines) ( $n=40,23 \%)$

Safe procurement principles (e.g. to ensure purchase of medicines with appropriate quality, pharmaceuticals complying with specifications) ( $n=34,20 \%)$

Principles of safeguarding the pharmaceutical supply chain (e.g. pharmaceutical supply chain management, industrial pharmacy quality requirements) $(n=34,20 \%)$

Education of patients (e.g. opportunistic counselling on risks of obtaining medicines from unauthorised sources) $(n=30,17 \%)$

Education of the public (e.g. raising public awareness) ( $n=27,16 \%)$

None of the above $(n=7,4 \%)$

Quality Control (e.g. pharmacopeia, compliance with regulatory requirements) ( $n=44,26 \%$ )

Pharmaceutical analysis and principles of chemical inspection of the medical product through laboratory

testing (e.g. dissolution test, chromatography) ( $n=40,24 \%)$

Pharmacovigilance $(n=33,19 \%)$

Principles of physical inspection $(n=31,18 \%)$

Detection tools and verification systems (e.g. medicines tracking, portable screening devices) $(n=17,10 \%)$

None of the above $(n=5,3 \%)$

Reporting through national authorities $(n=36,33 \%)$

Reporting up the supply chain (e.g. performing batch recall) $(n=22,20 \%)$

None of the above $(n=15,14 \%)$

Principles and advantages of data collecting and sharing incidence of SF medical products ( $n=14,13 \%)$

Reporting through international authorities (WHO Rapid Alert Form) ( $n=11,10 \%)$

Importance of the development of reporting systems (e.g. smartphone applications) ( $n=11,10 \%)$

Recognising the effects of exposure to SF medical products (e.g. pharmacology, toxicology of (SF) medical products) ( $n=27,19 \%)$

Counselling in case of exposure to SF medical products $(n=22,15 \%)$

Providing pharmaceutical care in case of the effects of exposure to SF medical products $(n=21,15 \%)$

Communication of information on incidence to colleagues, patients and public ( $n=21,15 \%)$

Obtaining and documenting relevant patient medication history $(n=18,13 \%)$

None of the above $(n=18,13 \%)$

Referring to follow-up care $(n=17,12 \%)$

Note: Modules are corresponding to the curriculum for pharmacy students on substandard and falsified medicines of the FIP (FIP (International Pharmaceutical Federation), 2021) that contains six Modules (A-F) integrating trainings elements for pharmacists.

$\dagger$ Answers "None of the above" were excluded.

${ }^{\ddagger}$ For example, when a pharmacy institute taught about SF medical products, Module A would represent on average $16 \%$ of the subject being taught.

The competencies that were linked most to the learning outcomes of SF medical products were appropriate communications to educate, build, report and engage healthcare professionals $(n=31,56 \%)$ and patients concerning SF medical product incidents ( $n=29,53 \%)$ (Figure 3). 


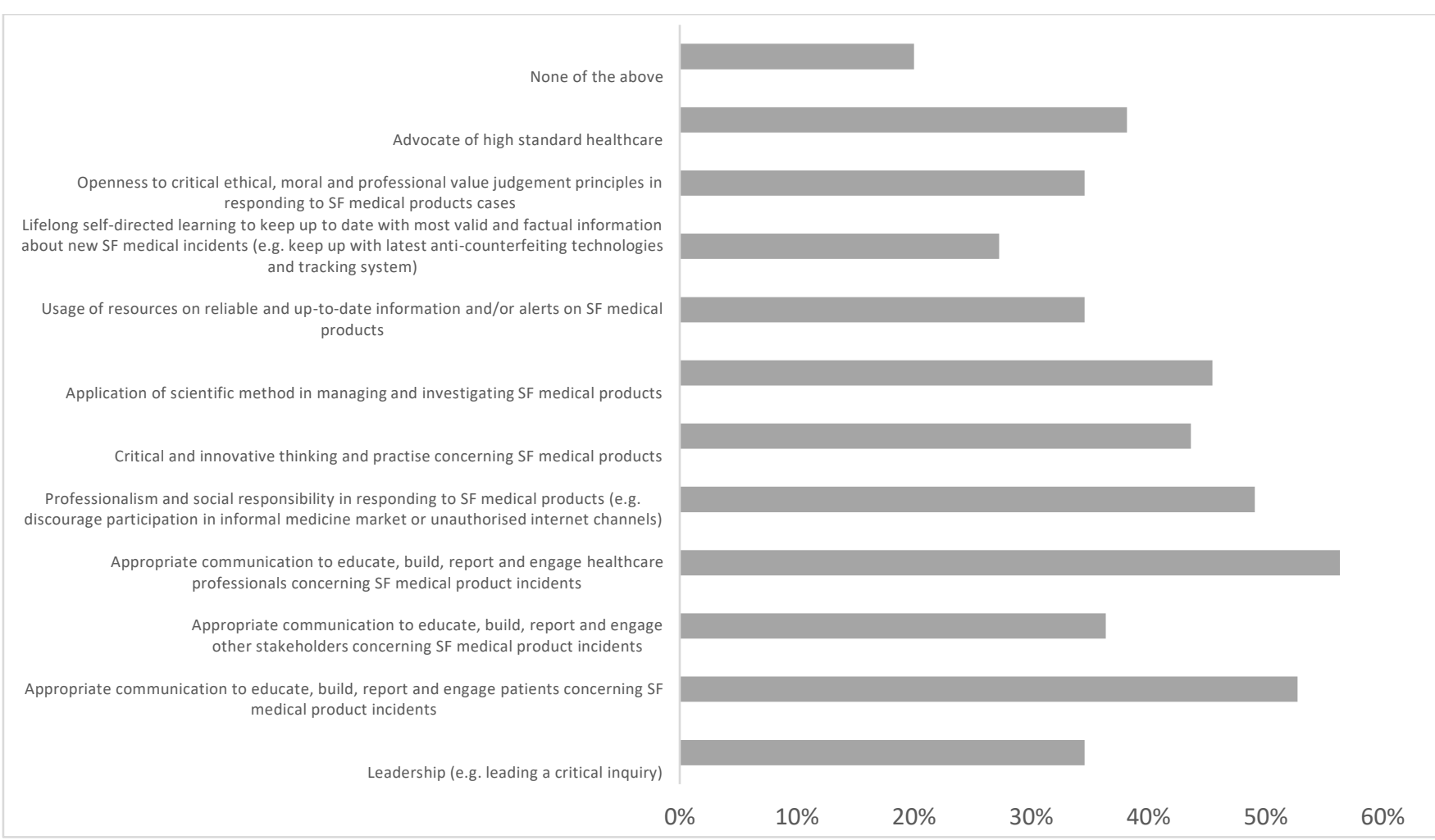

Figure 3: Competencies that are linked by participants to learning outcomes of SF medical product-related courses (multiple answers possible, $\%, n=55$ )

\section{Barriers and enablers for introducing a new module in} the pharmacy curriculum

Approval of the introduction of a new module in the existing pharmacy curriculum was for the most part done by the Head/Director of the institution ( $n=30,55 \%)$, proceeded by a regulatory body $(n=22,40 \%)$, the
Ministry of Health $(n=3,5 \%)$ or other $(n=19,35 \%)$, mainly curriculum committees or programme councils.

With regard to barriers for the implementation of a new module the most prevalent problem was not having sufficient space in their pharmacy curriculum $(n=33$, $60 \%$ ) and lack of educator's time to deliver classes $(n=17$, 31\%) (Figure 4).

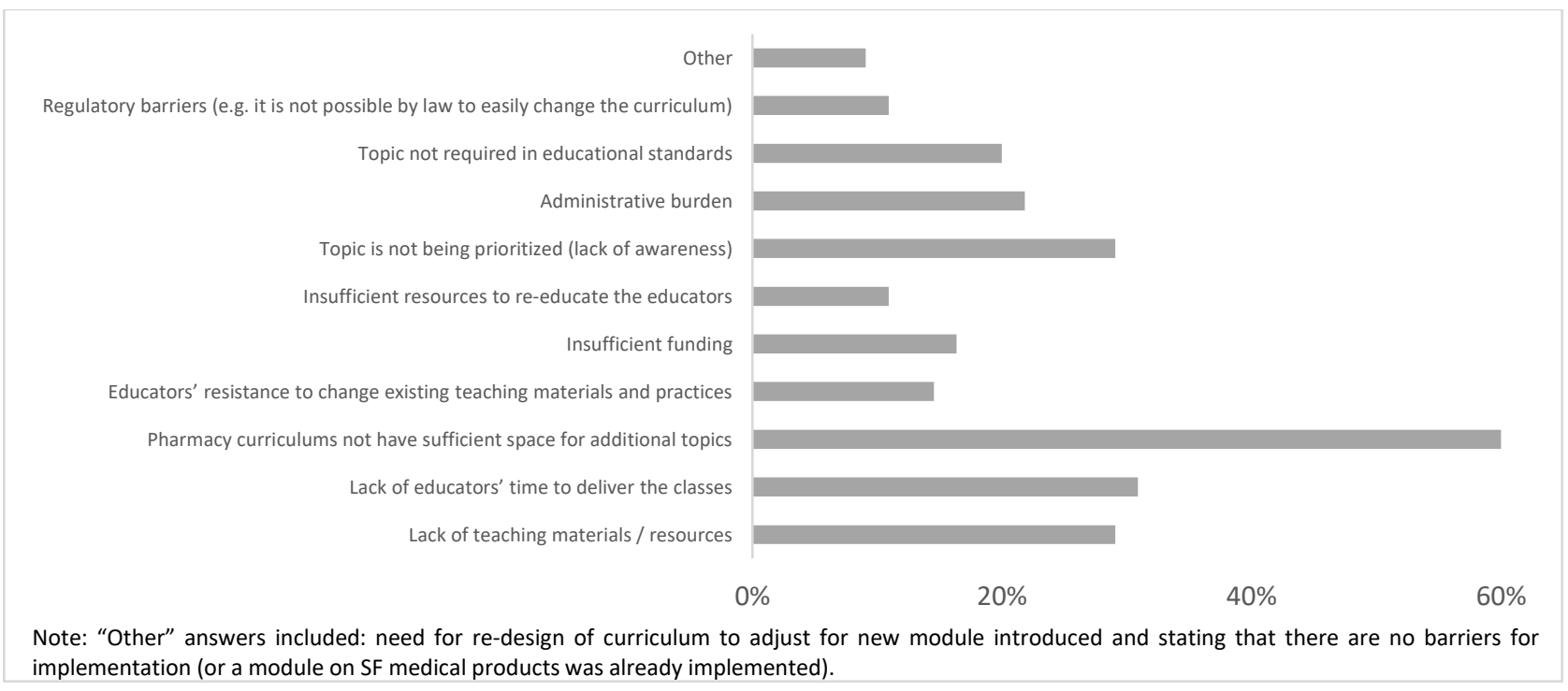

Figure 4: Barriers for implementation of a new module (multiple answers possible, $\%, n=55$ ) 
Regarding enablers, most institutions ( $n=27,50 \%)$ indicated that implementation of a new module would be most likely enabled by an existing course on SF medical products that is ready-to-adopt and integrated as part of an existing course (Table IV).

Table IV: Intentions of SF medical products course

\begin{tabular}{lccccc}
\hline Introduction as: & Mean (SD) & Not at all, \\
No. (\%) & $\begin{array}{c}\text { Not very likely, No. } \\
\text { (\%) }\end{array}$ & $\begin{array}{c}\text { Neutral, } \\
\text { No. (\%) }\end{array}$ & $\begin{array}{c}\text { Likely, No. } \\
\text { (\%) }\end{array}$ & $\begin{array}{c}\text { Very likely, } \\
\text { No. (\%) }\end{array}$ \\
\hline Stand-alone module ${ }^{\ddagger}$ & $3.2(1.3)$ & $6(11)$ & $13(24)$ & $7(13)$ & $19(35)$ \\
\hline Part of an existing course & $4.3(0.9)$ & $1(2)$ & $1(2)$ & $5(9)$ & $20(37)$ \\
\hline
\end{tabular}

Abbreviations: $\mathrm{SD}=$ standard deviation, No. = numero, number

${ }^{+}$Based on a five-point Likert Scale on which $1=$ not at all and $5=$ very likely

₹54 participants answered

Most institutions agreed with the statement that their students were adequately equipped to detect and take action if exposed to substandard and falsified medical products after graduation. Furthermore, almost all of the institutions agreed with the statement that their institution was able to readily identify and include new skills/competencies in the pharmacy curriculum as they emerge in practice (Table V).

Table V: Agreement with statements on student competencies and skills in practice

\begin{tabular}{|c|c|c|c|c|c|c|}
\hline & $\begin{array}{l}\text { Mean } \\
(\mathrm{SD})^{\dagger}\end{array}$ & $\begin{array}{c}\text { Strongly } \\
\text { disagree, } \\
\text { No. (\%) }\end{array}$ & $\begin{array}{c}\text { Disagree, } \\
\text { No. (\%) }\end{array}$ & $\begin{array}{l}\text { Neutral, } \\
\text { No. (\%) }\end{array}$ & $\begin{array}{l}\text { Agree, } \\
\text { No. (\%) }\end{array}$ & $\begin{array}{c}\text { Strongly } \\
\text { agree, No. } \\
(\%)\end{array}$ \\
\hline $\begin{array}{l}\text { My students are equipped with the } \\
\text { competencies to detect and take action if } \\
\text { exposed to substandard and falsified medicines } \\
\text { after graduation }{ }^{\ddagger}\end{array}$ & $3.6(1.0)$ & $1(2)$ & $9(16)$ & $10(18)$ & $24(44)$ & $11(20)$ \\
\hline $\begin{array}{l}\text { In the light of SF medical products becoming a } \\
\text { major threat, my institution of pharmacy is able } \\
\text { to readily identify and include new } \\
\text { skills/competencies in the pharmacy } \\
\text { curriculum as they emerge in practice }\end{array}$ & $4.1(0.8)$ & $1(2)$ & $0(0)$ & $11(20)$ & $23(42)$ & $20(36)$ \\
\hline
\end{tabular}

Abbreviations: SD = standard deviation, No. = numero, number

${ }^{+}$Based on a five-point Likert Scale on which $1=$ strongly disagree and $5=$ strongly agree

₹ 55 participants answered

\section{Discussion}

This study was conducted to understand how and to what extent the topic of substandard or falsified (SF) medical products courses are taught in pharmacy educational institutions around the world. This study found that one out of three pharmacy schools does not offer any targeted education on SF medical products. Only two of the responding universities taught a standalone course on SF medical products, and a majority of schools taught about SF medical products as part of another course. For the institutions that do teach about SF medical products, the study found that the majority of schools tended to do this in the middlelater years. This can be due to the need for prerequisite courses for students enrolled in such courses. These were reported to be mostly analytical chemistry (qualitative and quantitative analysis), to understand the detection strategies and analytical tools that can be used for this purpose, as well as pharmaceutical chemistry and pharmaceutical quality assurance and control necessary to understand the issues related to substandard products. Pharmaceutical policies and regulations, as well as the basics of pharmacology and toxicology for the clinical understanding of impact are other important prerequisites for the SF medical products courses. When considering the implementation of SF medical products courses in the future, schools should take into consideration the courses students have to take and pass before they are ready to take the SF course.

Universities that have been teaching matters related to SF medical products reported using traditional methods (e.g. lectures, seminars, tutorials) and teaching in classroom setting as the most dominant one, and written exams being the most common assessment. The educators were typically universityemployed pharmacists with regular or minimal patient contact. However, the competency development framework developed by FIP (FIP (International Pharmaceutical Federation), 2021) recommends that 
some of the modules, such as the modules on detection or reporting, are to include some non-traditional methods like problem-, team- and case-based learning, and in practice settings (e.g. in hospital). This can provide students with a relevant opportunity to see theory in practice, and require them to develop analytic, communicative and collaborative skills along with content knowledge. Such an approach, however, was reported by only half of the respondents.

The most common teaching topics regarding SF medical prducts are focused on modules concerning the prevention and detection of SF medical products. This can be explained by the fact that analytical chemistry is a common part of pharmacy curricula around the globe. They already contain basics of qualitative and quantitative analysis, important for quality assurance and detection of substandard products (Accreditation council for pharmacy education, 2015; FIP (International Pharmaceutical Federation), 2020). This corresponds to the findings from this study, as Quality Control (e.g. pharmacopeia, compliance with regulatory requirements) was reported to be the most taught subtopic.

The topics on identification of characteristics of medical products that are most at risk of being substandard and/or falsified were less prevalent. The results revealed the biggest gaps were in the topic of reporting of SF medical products, which was being taught the least. However, one third of all schools did not teach any of the listed topics. Gaps were also identified in the topics around patient intervention, where 15 out of 55 schools indicated that there was no content regarding recognising or counselling on the effects of exposure to SF medical products or providing pharmaceutical or follow-up care in case of exposure to SF medical products. Neither obtaining or communicating related information and documentation on incidence to colleagues, patients and public. However, literature argues that pharmacists do need to understand how substandard and falsified medical products affect pharmacy practice and their detrimental effects on health. Ferrairo and Wirtz (2019) highlighted that including mandatory education on SF medical products (e.g. a module on 'Quality of Medicines and Public Health') in basic pharmacists' training would ensure that all incoming workforce are exposed to the same foundation. This would be more sustainable than ad hoc training on the job (e.g. for regulatory authorities), which requires additional resources (Ferrario et al., 2019). Findings from this survey study, specifically the overview of teaching content corresponding to the content areas of the FIP curriculum (Table III), could provide a starting point to help academics understand where the gaps in content are the most prevalent and where they most likely need to be closed.
Most institutions agreed with the statement that their students were adequately equipped to detect and take action if exposed to SF medical products after graduation and almost all of the institutions agreed that their institution was able to readily identify and include new skills/competencies in the pharmacy curriculum as they emerge in practice. While this finding is rather optimistic, based on the content gaps, the authors argue there is still much to do in establishing a ready and responsive pharmacy education to meet the fastpaced challenges in public health. Future studies are needed to measure the impact of SF medical products education on combatting SF medical products in practice.

In addition, this study identified possible barriers and enablers in introducing a new course or module into the pharmacy curriculum. The majority of schools indicated that the most common barrier for the implementation of a new module was the lack of sufficient space in their pharmacy curriculum. Over one third indicated that the educators lacked the time to deliver classes, this had also been noted in previous studies where a lack of time in medical-related curricula was rated the most significant barrier (Aiyer et al., 2002; Meats et al., 2009; Blanco et al., 2014). For example, Blanco and the authors (2014) found the "lack of time in curriculum' to be a significant barrier in implementing an evidence-based medicine curriculum in the United States and Canadian medical schools (Blanco et al., 2014). On the other hand, the regulatory barriers were indicated as the least impactful, e.g. not being able to easily change the curriculum by law. This can be explained by the fact that approval of the introduction of a new module in the existing pharmacy curriculum was reported for the most part to be done by the Head/Director of the institution.

Some of the barriers to the introduction of a course on SF medical products can be overcome by the availability of the ready-to-adopt curriculum as an enabler to change. The majority of respondents indicated that if a standalone module (supported by a competency framework) on SF medical products is available, it would be very likely to be introduced as part of an existing course and likely to be introduced as a standalone course. Meats and the authors also recommend that having a common competency framework would further inform and guide curricular efforts to close the gaps in teaching (Meats et al., 2009). More studies are needed to understand the barriers and enablers specific to implementing courses or modules addressing new topics in an undergraduate pharmacy curriculum at a global level.

One such course was developed by the FIP in collaboration with the WHO specifically for countries most vulnerable to SF medical products: low-income 
countries, and in particular, Sub-Saharan Africa (World Health Organization, 2017a). In 2019, an initiative to enhance training on SF medical products in pharmacy curricula was introduced as a joint pilot project funded by the European Commission (EC) and led by the WHO and FIP, with contribution of the Francophone Order of Pharmacists (CIOPF) and the Commonwealth Pharmacists' Association (CPA). They work together on developing a compulsory education component on SF medical products in five pilot Universities in Africa (FIP (International Pharmaceutical Federation), 2021). The project aims to develop and deploy a curriculum on the threat of SF medical products as a compulsory education component for undergraduate pharmacy students in Sub-Saharan Africa, where the need is great. The project is currently running, with the estimated completion planned for 2021. In addition, FIP has been working on educational reforms to advance research, training, and curriculum development in pharmacy education (FIP (International Pharmaceutical Federation), 2020). Such projects can be beneficial enablers for universities who would like to adopt the curriculum in the future.

\section{Limitations}

This survey is the first global study to bring insight into the education in substandard and falsified (SF) medical products in schools of pharmacy around the world. The schools of pharmacy listed in the FIP Academic Institutional Members database were surveyed. This database gathers internationally active schools of pharmacy and pharmaceutical sciences and despite it does not contain all the pharmacy schools around the globe, it provided a good starting point for this research.

This survey covered respondents across all the WHO regions. However, there was a skewed distribution among the different income groups; for example, this study did not have respondents from low-income countries. Therefore, our results cannot directly be translated to low-income countries, even though SF medicines are mostly a problem in low- and middleincome countries (World Health Organization, 2017a; Ozawa et al., 2018). On initial scanning of the data, the authors found no apparent differences in results between high and middle income countries, and low numbers hampered any strong conclusions on the differences. It is worth noting that the survey was running during the COVID-19 pandemic, which may have negatively impacted the response rate due to university lockdowns. Finally, among surveyed academics, the respondents were mostly deans or directors, and this may interfere with the extent of their knowledge with regards to details of teaching activity in the institution and thus might be underreported in our results.

Considering the limitations cited, the survey presents mapping in terms of teaching content, skills and knowledge gap as well as readiness or possible barriers exacerbating the gap. It is providing supporting evidence for highlighting the gap in SF medical products education and can be used to support universities in changing curricula to include modules on this topic, as well as guide frameworks and policies at the institutional, national, or regional level. It can also inform the initiatives at global level, e.g. joint FIP-WHO projects on training on SF medical products on the existing gaps.

\section{Conclusions}

While this study found that the majority of pharmacy schools do not offer any dedicated standalone education on SF medical products, most of the pharmacy schools do offer some teaching on SF medical products as part of existing curricula, mostly concerning the prevention and detection of SF medical products. This study found significant gaps in the teaching content, mostly in reporting of SF medical products, but also in teaching methods. Availability of ready-to-adopt curriculum materials can help overcome some of the barriers to their implementation, leading to better prepared pharmacists in combatting SF medical products. Future research should focus on the best way to integrate information on SF medical products, as well as to measure the impact of SF medical products education on combatting SF medical products in practice.

\section{Conflicts of interest}

The authors report no conflict of interest. The views expressed in this article are the personal views of the authors and must not be understood or quoted as being made on behalf of the International Pharmaceutical Federation.

\section{Acknowledgments}

The authors would like to thank Dr Catherine Duggan, the CEO of the International Pharmaceutical Federation (FIP) for the final review of this article and for her supervision during the conduct of this study. 


\section{References}

Accreditation council for pharmacy education. (2015). Accreditation standards and key elements for the professional program in pharmacy leading to the doctor of pharmacy degree. Chicago

Aiyer, M., Hemmer, P., Meyer, L., Albritton, T. A., Levine, S., \& Reddy, S. (2002). Evidence-based medicine in internal medicine clerkships: a national survey. Southern medical journal, 95(12), 1389-1395. United States. https://doi.org/10.1097/00007611-200295120-00007

Blanco, M. A., Capello, C. F., Dorsch, J. L., Perry, G., \& Zanetti, M. L. (2014). A survey study of evidence-based medicine training in US and Canadian medical schools. Journal of the Medical Library Association : JMLA, 102(3), 160-168. Medical Library Association. Retrieved from https://pubmed.ncbi.nlm.nih.gov/25031556 https://doi.org/10.3163/1536-5050.102.3.005

Director General Seventieth World Health Assembly. (2017). A70/23 - Member State Mechanism on

Substandard/Spurious/Falsely-labelled/Falsified/Counterfeit Medical Products. Retrieved from

https://www.who.int/medicines/regulation/ssffc/mechanis m/A70_23-en6-14.pdf?ua=1

Ferrario A, Wirtz VJ, Z. M. (2018). Education about substandard and falsified medicines: a review of Bachelor in Pharmacy curricula in six countries. Medicine Quality \& Public Health Conference. Oxford

Ferrario, A., Orubu, E. S. F., Adeyeye, M. C., Zaman, M. H., \& Wirtz, V. J. (2019). The need for comprehensive and multidisciplinary training in substandard and falsified medicines for pharmacists. BMJ Global Health, 4(4), e001681. https://doi.org/10.1136/bmjgh-2019-001681

FIP (International Pharmaceutical Federation). (2018). Pharmacists in the supply chain: The role of the medicines expert in ensuring quality and availability. The Hague

FIP (International Pharmaceutical Federation). (2020). FIP pharmacy education in sub-Saharan Africa - The FIPUNESCO UNITWIN Programme: A decade of education partnership across Africa

FIP (International Pharmaceutical Federation). (2021). Curriculum for pharmacy students on substandard and falsified medicines. The Hague. Retrieved from https://www.fip.org/file/4917

International Association of Medical Regulatory Authorities. (n.d.). What is a medical regulatory authority? Retrieved January 2, 2021, from https://www.iamra.com/What-is-aMedical-Regulatory-Authority\#: :text=Medical Regulatory Authority\%3F-, What is a medical regulatory authority\%3F,profession of medicine\%3B and\%2For

Kheir, N., Zaidan, M., Younes, H., El Hajj, M., Wilbur, K., \& Jewesson, P. J. (2008). Pharmacy education and practice in 13 Middle Eastern countries. American journal of pharmaceutical education, 72(6), 133. American Journal of Pharmaceutical Education. Retrieved from https://pubmed.ncbi.nlm.nih.gov/19325953 https://doi.org/10.5688/aj7206133

Meats, E., Heneghan, C., Crilly, M., \& Glasziou, P. (2009). Evidence-based medicine teaching in UK medical schools. Medical teacher, 31(4), 332-337. England. https://doi.org/10.1080/01421590802572791

Medina, M. S., Plaza, C. M., Stowe, C. D., Robinson, E. T., DeLander, G., Beck, D. E., Melchert, R. B., et al. (2013). Center for the Advancement of Pharmacy Education 2013 educational outcomes. American journal of pharmaceutical education, 77(8), 162. American Journal of Pharmaceutical Education. Retrieved from https://pubmed.ncbi.nlm.nih.gov/24159203 https://doi.org/10.5688/ajpe778162

Ozawa, S., Evans, D. R., Bessias, S., Haynie, D. G., Yemeke, T. T., Laing, S. K., \& Herrington, J. E. (2018). Prevalence and Estimated Economic Burden of Substandard and Falsified Medicines in Low- and Middle-Income Countries: A Systematic Review and Meta-analysis. JAMA Network Open, 1(4), e181662-e181662.

https://doi.org/10.1001/jamanetworkopen.2018.1662

Pyzik, O. (2018). Global Pharmacy Education \& UCL Fight the Fakes. Medicine Quality \& Public Health Conference. Oxford.

World Bank. (2020). World Bank list of economies (June 2020). Retrieved from https://databank.worldbank.org/data/download/sitecontent/CLASS.xIs

World Health Organization. (2017a). WHO Global Surveillance and Monitoring System for substandard and falsified medical products. Geneva.

World Health Organization. (2017b). Seventieth World Health Assembly. Retrieved from https://www.who.int/medicines/regulation/ssffc/A70_23en1.pdf?ua=1

World Health Organization. (2019). Agreed list of prioritized activities to implement the workplan of the member state mechanism for the periode 2020-2021. Retrieved from https://www.who.int/medicines/regulation/ssffc/mechanis m/A_MSM8_4-en-6-8.pdf?ua=1

World Health Organization. (2020). World Health Statistics 2020: : monitoring health for the SDGs, sustainable development goals. Retrieved from https://www.who.int/data/gho/publications/world-healthstatistics

World Health Organization. (n.d.). Essential medicines and health products - WHO Member State Mechanism. Retrieved from https://www.who.int/medicines/regulation/ssffc/mechanis $\mathrm{m} / \mathrm{en} /$ 


\section{Appendix A: Specific course(s) and/or lecture(s) given about SF medical products}

\begin{tabular}{|c|c|}
\hline Main subject & Subtopics \\
\hline $\begin{array}{l}\text { Pharmaceutical analysis } \\
\text { (analytical chemistry) }\end{array}$ & $\begin{array}{l}\text { Pharmaceutical analysis; including quantitate and qualitative analysis } \\
\text { Pharmacognosy; physical inspection and qualitative tests for medical plants } \\
\text { Analytical chemistry; analytical techniques and procedures to detect substandard products } \\
\text { Physical Pharmaceutics and Formulation; scientific concepts behind designing and using liquid or semi- } \\
\text { solid pharmaceutical dosage forms to deliver a drug }\end{array}$ \\
\hline Quality Assurance & $\begin{array}{l}\text { Drug dissolution systems (DDS); product quality specification during dissolution section of DDS; } \\
\text { definitions and examples of adulteration and misbranding during DDS; during discussion of raw material } \\
\text { quality as part of micromeritics and formulation sections of DDS; brief reference to shipment tracking in } \\
\text { DDS. } \\
\text { Quality assurance and role of qualified person } \\
\text { Criteria for quality of medical products vs counterfeit products, quality control of tablets, capsules, } \\
\text { creams, ointments, emulsion, suspension and other pharmaceutical products; dosage forms and drug } \\
\text { delivery; medicines standardisation } \\
\text { Pharmaceutical technologies and biopharmacy } \\
\text { Pharmacopeia and national formulary; in relation to active pharmaceutical ingredients and excipients } \\
\text { Good manufacturing practice } \\
\text { Internet and medicines (quality aspects) } \\
\text { Advanced medicine supply management } \\
\text { Reporting SF medical products; medicines verification system } \\
\text { Registration of products and National Pharmaceutical Regulatory Affairs Agency; marketing } \\
\text { authorisation process; principles of New Drug Application (NDA) of Investigational New Drug (IND); } \\
\text { labelling; orphan medicines } \\
\text { Forensic pharmacy } \\
\text { Regulations and standards for pharmacy } \\
\text { Pharmacy law } \\
\text { Pharmacovigilance }\end{array}$ \\
\hline
\end{tabular}

Regulatory sciences Drug dissolution systems (DDS); product quality specification during dissolution section of DDS; definitions and examples of adulteration and misbranding during DDS; during discussion of raw material quality as part of micromeritics and formulation sections of DDS; brief reference to shipment tracking in DDS.

Quality assurance and role of qualified person

Criteria for quality of medical products vs counterfeit products, quality control of tablets, capsules, creams, ointments, emulsion, suspension and other pharmaceutical products; dosage forms and drug delivery; medicines standardisation

Pharmaceutical technologies and biopharmacy

Pharmacopeia and national formulary; in relation to active pharmaceutical ingredients and excipients Good manufacturing practice

Internet and medicines (quality aspects)

Advanced medicine supply management

Reporting SF medical products; medicines verification system

Pharmaceutical Policy Health, pharmaceutical, and medicines legislation

(analysis) Legal framework and quality standards; definition of substandard drugs

Economy of the SF medical products market

Falsified Medicines Directive (FMD): introduction, explanation; difference between falsified and counterfeit medicines

Pharmaceutical industry Good manufacturing practice; GXP; Quality Management Systems Industrial pharmacy

Pharmacology Principles of medicines action

Toxicology

Principles of pharmaceutical toxicology; medical consequences of SF medical products

Pharmacoepidemiology Principles of pharmacoepidemiology

Pharmacy practice and Regulating manufacturing and distribution of medicines

pharmaceutical care Foundations of Pharmacy; complementary and alternative medicines

Health care systems

Global and public health; the dangers of SF on public health, the role of pharmacist in public awareness and education

Ethics

The Role of good pharmacy practice in detecting and reporting SF medical products

Dispensing in pharmacy; pharmaceutical ethics and jurisprudence

Pharmaceutical supply chain management (medicines and medical supplies management)
The role of packaging; security labels of primary and secondary packaging :

Risk and costs of SF medical products; tracking technologies and technological advancements; prevention of SF medical products in the supply chain 


\section{Appendix B: Materials used to teach about the SF medical products}

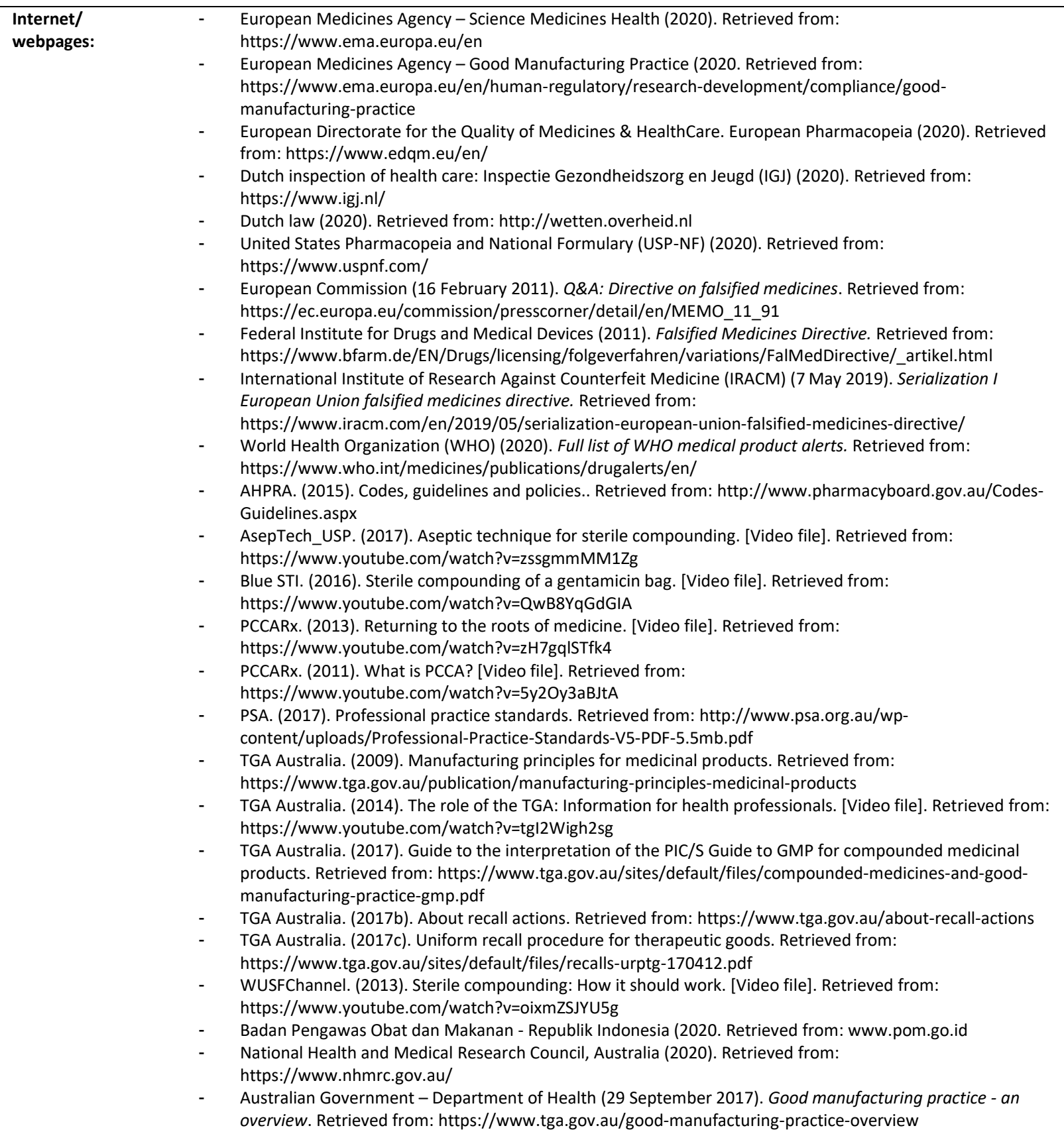

Textbooks $\quad$ - Management Sciences for Health. MDS-3: managing access to medicines and health technologies. Arlington, VA: Management Sciences for Health. Harris DC. Quantitative Chemical Analysis. $7^{\text {th }}$ (2007) or $8^{\text {th }}$ (2010) edition

- Cartwright AC, and Matthews BR. International Pharmaceutical Product Registration British Pharmacopeia (2020). Retrieved from: www.pharmacopoeia.com Moffat AC, Osselton MD, Widdop B, Watts J. Clarke's Analysis of Drugs and Poisons. Ahuja S, and Sapinski S. Handbook of Modern Pharmaceutical Analysis Royal Society of Chemistry. Merck Index: An Encyclopaedia of Chemicals, Drugs, and Biologicals. Loyd AV. The Art, Science, and Technology of Pharmaceutical Compounding Davison M. Pharmaceutical Anti-Counterfeiting. Wiley, 2011 